\title{
LOWER LIMB FRACTURES WITH ASSOCIATED VASCULAR INJURY
}

\author{
PETER W. HOWARD, GEOFFREY S. MAKIN
}

\author{
From University Hospital, Nottingham and Derbyshire Royal Infirmary, Derby
}

\begin{abstract}
We report the management and outcome of 35 lower limb fractures with associated severe vascular injuries treated over a 15-year period. Limb survival was related to the period of ischaemia. Management of the fractures by immediate open reduction and internal fixation was associated with a higher amputation rate than either external fixation or simple splintage, particularly for upper tibial injuries. External fixation is recommended as the method of choice for the stabilisation of the skeletal injury. A selective policy is advised for fasciotomy.
\end{abstract}

Lower limb fractures complicated by vascular injuries are uncommon, with an incidence estimated at $0.1 \%$ (Porter 1967). A number of studies have examined the vascular aspects of such cases, but relatively little attention has been paid to the method of treatment of the fractures. Many of the largest series of such injuries have included a major proportion of penetrating war injuries (De Bakey and Simeone 1946; Rich et al 1969, 1974). Rich et al (1971) concluded that for battle injuries external stabilisation was preferable to internal fixation. External fixation is also recommended in some reports of civilian injuries (Allen et al 1984; Meek and Robbs 1984; Krige and Spence 1987), whilst others advocate primary internal fixation (Doty et al 1967). No comparative data is available for the civilian series, and the case for fasciotomy and pre-operative arteriography has also received little investigation.

Our study aimed to examine the outcome of lower limb fractures with associated major vessel disruption, and to assess the influence of the method of fracture treatment and the role of fasciotomy.

\section{PATIENTS AND METHODS}

We reviewed the case records and radiographs of all patients seen in Nottingham and Derby from 1971 to 1986 with fractures of the lower limb and associated

P. W. Howard, FRCS, Orthopaedic Registrar

The Royal Orthopaedic Hospital, Northfield, Birmingham B31 2AP, England.

G. S. Makin, FRCS, Consultant Vascular and General Surgeon

University Hospital, Queen's Medical Centre, Nottingham NG7 2UH, England.

Correspondence should be sent to Mr P. W. Howard.

(C) 1990 British Editorial Society of Bone and Joint Surgery $0301-620 \mathrm{X} / 90 / 1010 \$ 2.00$

J Bone Joint Surg [Br] 1990; 72-B: 116-20. major vascular disruption. The population at risk was 1.3 million, and 35 such cases were identified. An additional eight patients with vascular injuries but no skeletal involvement, and four who had such injuries associated with pelvic fractures all had excellent results and are not discussed further. Nine patients underwent primary amputation because the damage was too great and replantation was technically impossible.

Table I. Cause of injury

\begin{tabular}{ll}
\hline & Number \\
\hline Motorcyclist & 16 \\
Pedestrian & 7 \\
Car & 6 \\
Industrial & 4 \\
Other & 2 \\
\hline
\end{tabular}

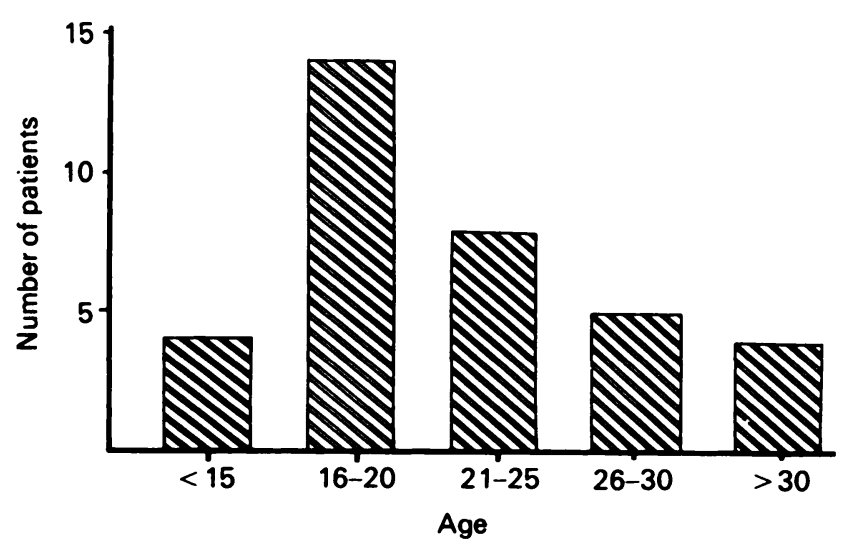

Fig. 1

Age distribution of patients. 
We recorded the age, the mechanism of injury, the fracture type and the method of fracture treatment, and also studied the use of fasciotomy and arteriography, the incidence of compartment syndrome, and the factors influencing eventual amputation.

\section{RESULTS}

The injuries occurred predominantly in young people (Fig. 1). In the study period there had been 1743 femoral and 2367 tibial fractures (excluding hip and ankle fractures), giving an incidence of major vascular damage of $0.8 \%$. The majority of patients were motorcyclists (Table I), and in addition four of the pedestrians had

Table II. Site and type of injury

\begin{tabular}{lll}
\hline & Closed & Compound \\
\hline Femur & 6 & 7 \\
Tibia & 6 & 8 \\
Femur and tibia & 1 & 5 \\
Knee dislocation & 1 & 1 \\
\hline
\end{tabular}

been hit by motorcycles. The nature and site of the skeletal injury is shown in Table II.

Vascular injury. The duration of ischaemia time is related to the outcome in Table III. As expected there is a clear relationship between the delay before revascularisation and amputation $(\mathrm{p}<0.002)$; the amputation rate was almost $50 \%$ when the duration of ischaemia exceeded eight hours.

All the vascular repairs were carried out by either consultant vascular surgeons, or senior registrars trained in vascular surgery. In 29 cases the vascular injuries were repaired using autogenous reversed saphenous vein. Of the others, four had thrombectomies with or without a vein patch, and two had direct end-to-end suture. In four cases a major vein was also repaired.

Skeletal fracture. Primary treatment of the skeletal injury was by open reduction and internal fixation, by external fixation or by simple splintage (Table IV). The outcome in terms of amputation was less favourable after primary internal fixation. Delayed or non-union was more common after external fixation, three patients developing gap fractures of the tibia which subsequently united after treatment by direct vascularised fibular transfer grafts (Figs 2 to 4 ).

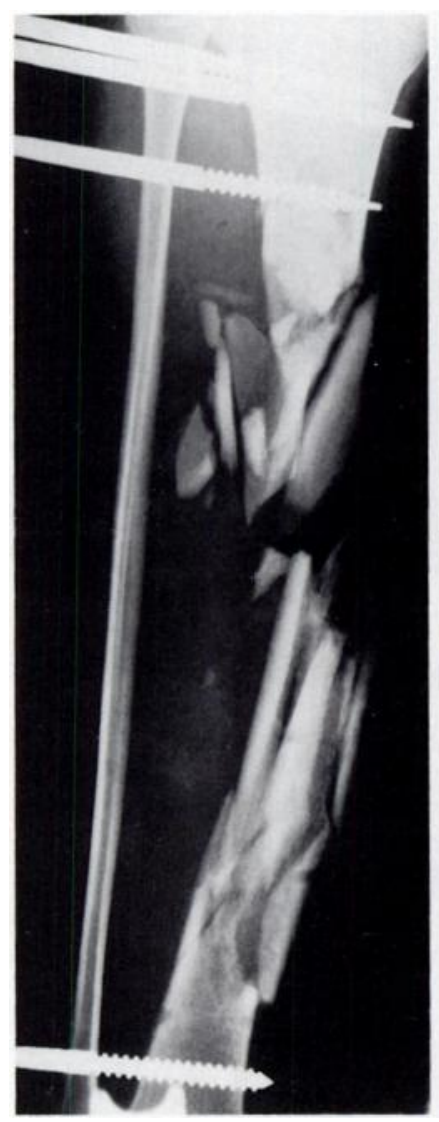

Fig. 2

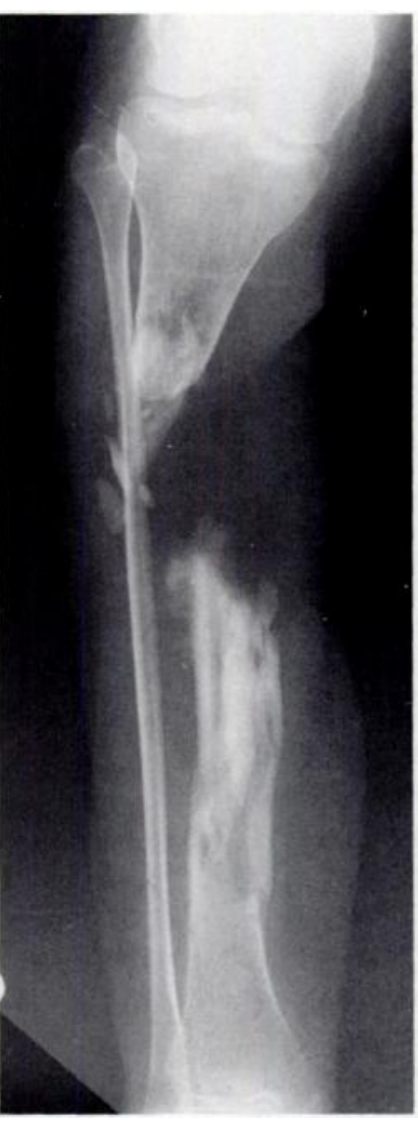

Fig. 3

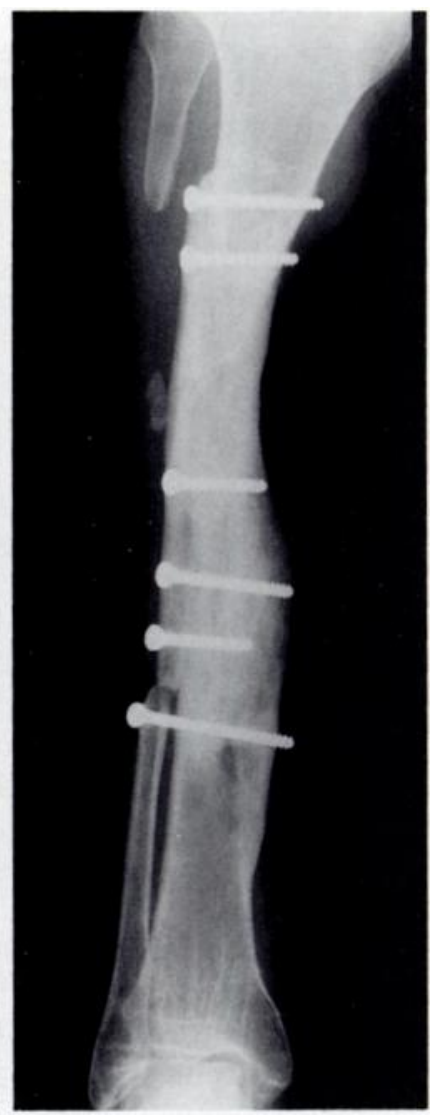

Fig. 4

Radiographs of a severe tibial fracture with a vascular injury, after stabilisation with external fixation, at six months when the soft tissues had healed, and finally after a fibular transfer graft. 
The methods used for primary internal fixation are shown in Table V. Patients with more severe soft tissue injuries tended to be treated by external fixation, particularly for the tibia. Despite this bias, limbs treated with external fixation fared better, although secondary surgery for bone and soft tissue reconstruction was more frequently required. One late amputation after external fixation was performed early in the series for extensive anterior soft tissue loss over the lower leg; more recently this would have been salvageable by a free myocutaneous flap.

Arteriography. Pre-operative arteriography was performed routinely on the operating table in 14 of the Derby cases, but only in four of the Nottingham cases, where there was doubt over the level of injury (Fig. 5). No double arterial lesions were seen, but there was one negative exploration at which an artery thought clinically to be severed was found to be intact. In the later years of the study there has been an increasing use of postreconstruction arteriography, and this has identified rectifiable problems in two patients.

Table III. Ischaemic time related to the result

\begin{tabular}{llll}
\hline & Result & & \\
\cline { 2 - 4 } $\begin{array}{c}\text { Total duration of } \\
\text { ischaemia (hours) }\end{array}$ & $\begin{array}{l}\text { Good or } \\
\text { excellent }\end{array}$ & $\begin{array}{l}\text { Below-knee } \\
\text { amputation }\end{array}$ & $\begin{array}{l}\text { Above-knee } \\
\text { amputation }\end{array}$ \\
\hline$<8^{*}$ & 23 & 1 & 1 \\
8 to $12^{*}$ & 5 & 1 & 3 \\
Total & 28 & 2 & 5 \\
\hline
\end{tabular}

* difference $\mathrm{p}<0.02$ (chi-squared test with Yates correction)

Fasciotomy. Fasciotomy was not used routinely during the 15 years of the study, but more recently its use at the time of operation has increased. Since the more severely injured limbs were more likely to have a primary prophylactic fasciotomy, the results are uncontrolled and few conclusions can be drawn.

However, the outcome after primary fasciotomy tended to be worse (Table VI), and two patients who had prophylactic fasciotomies for arterial lesions associated with femoral fractures, later developed deep infection of their tibial fractures.

Amputation. Three limbs came to amputation because of early vascular failure, and three for extensive distal necrosis, one in each group with a probable compartment syndrome. One was for infection after considerable loss of tissue. Five of the amputations were during the first week after injury. Secondary exploration of arteries for occlusion after initial revascularisation produced no successes; all three cases resulted in amputation.
Long-term outcome. At the time of review, no patient had required additional arterial surgery and three patients had had successful knee ligament augmentation.

\section{DISCUSSION}

A more aggressive approach to vascular injuries has been advocated for some time (Makin, Howard and Green 1966), but since then many series have been reported with a poor outcome (Porter 1967; Allen et al 1984; Wilson et al 1986). It is plain that the duration of ischaemia time is closely related to the outcome, and the urgency of recognition and reconstruction cannot be overemphasised. In our series the use of reversed saphenous grafts has been almost uniform, with a low rate of vascular failure.

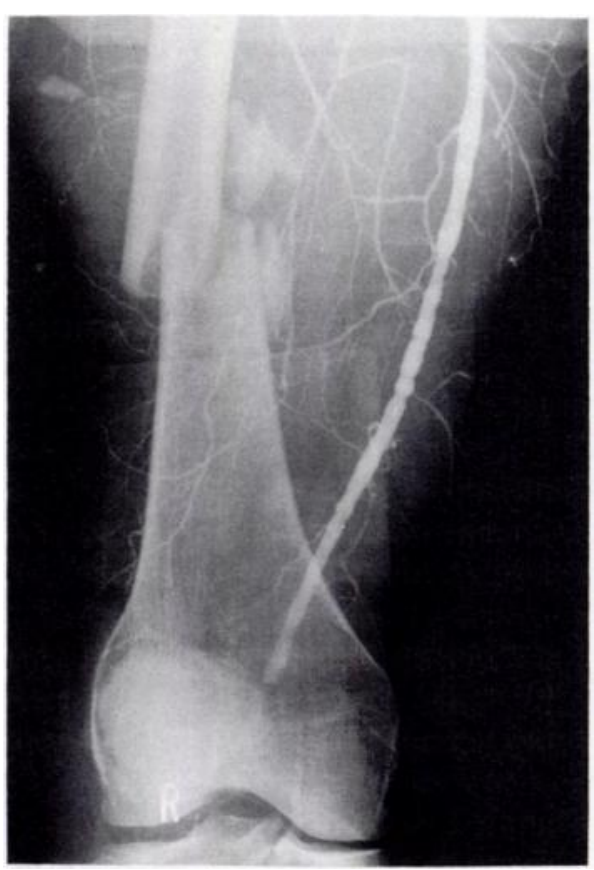

Fig. 5

Arteriogram of a limb with both femoral and tibial fractures. The vascular injury was of the distal popliteal artery.

Pre-operative arteriography is not necessary in most cases, as the site and nature of the problem is clinically apparent, and the additional ischaemic time is potentially detrimental. If arteriography is needed, this is most expediently done by direct femoral puncture in theatre; we recommend that this is reserved for cases of doubt over the diagnosis and the level of injury. Postreconstruction arteriography is recommended to identify anastomotic and distal problems; if these are neglected they are likely to become unsalvageable. 
Few authors have studied the influence of different methods of fracture management. Waddell and Lenczner (1974) found no difference in outcome between plaster, external fixation, and internal fixation. Doty et al (1967) favoured internal fixation, whilst Connolly, Whittaker and Williams (1971) and Rich et al (1971) found worse results in limbs which had been internally fixed. The potential value of internal fixation is the rigid and definitive fixation it offers. Against this, however, it necessarily compromises the collateral circulation of the limb when its vascularity is critical. The added soft-tissue disruption associated with open reduction and internal fixation may tip the balance between limb survival and amputation.

Table IV. Method of fracture treatment related to result

\begin{tabular}{llllll}
\hline & & \multicolumn{3}{l}{ Result } \\
\cline { 3 - 6 } & Number & Good & $\begin{array}{c}\text { Delayed or } \\
\text { nom-union }\end{array}$ & $\begin{array}{l}\text { Below-knee } \\
\text { amputation }\end{array}$ & $\begin{array}{c}\text { Above-knee } \\
\text { amputation }\end{array}$ \\
\hline $\begin{array}{l}\text { Internal } \\
\text { fixation }\end{array}$ & $15^{*}$ & 10 & 4 & 1 & 4 \\
$\begin{array}{l}\text { External } \\
\text { fixation }\end{array}$ & 12 & 8 & 4 & 1 & 1 \\
$\begin{array}{l}\text { Traction } \\
\text { or plaster }\end{array}$ & 8 & 8 & 4 & - & - \\
\hline
\end{tabular}

* amputation rate significantly higher for internal fixation than the remainder, $\mathrm{p}<0.01$ (chi-squared test with Yates correction)

Table V. Method of internal fixation (number coming to amputation in parentheses)

\begin{tabular}{llll}
\hline \multicolumn{1}{c}{$\begin{array}{l}\text { Dynamic } \\
\text { compression plate }\end{array}$} & $\begin{array}{l}\text { Blade or } \\
\text { buttress plate }\end{array}$ & $\begin{array}{l}\text { Intramedullary } \\
\text { nail }\end{array}$ \\
\hline Femur & $4(1)$ & $2(1)$ & $4(1)$ \\
Tibia & $3(1)$ & $2(1)$ & - \\
\hline
\end{tabular}

The results of our study indicate that, for the initial management of the fracture, external fixation is the treatment of choice, particularly for injuries at and below the knee. When simple splintage can provide adequate stability, this may safely be used. Femoral shaft fractures can probably be safely treated with intramedullary nailing, either delayed or immediate.

Once limb salvage has been achieved, and the soft tissues have stabilised, then definitive treatment of the skeletal injury can be performed. The high incidence of non-union in our series supports the use of early supplemental bone grafting, with or without internal fixation.

The place for prophylactic fasciotomy is unclear.
This is not without complications, as we have shown, and certainly the available data does not support its routine use. A policy of selective fasciotomy for injuries at the level of the knee, particularly those with prolonged ischaemic intervals seems to be appropriate. Careful clinical monitoring and the measurement of compartment pressures is essential for other cases.

It seems unlikely that the use of temporary prosthetic vascular shunts will improve results, since this has little effect on the total duration of ischaemia. External fixation is an expedient method, and may be performed before or after vascular repair. It is possible that the use of shunting would encourage more elaborate skeletal intervention, which our results suggest is contra-indicated.

Table VI. Fasciotomy related to result

\begin{tabular}{lll}
\hline Result & Fasciotomy & No fasciotomy \\
\hline Good & 7 & $21^{*}$ \\
Amputation & $5 \dagger$ & 2 \\
\hline $\begin{array}{l}\text { * three possibly missed } \\
\text { dromes }\end{array}$ \\
$\begin{array}{l}\text { tone performed late } \\
\text { on }\end{array}$
\end{tabular}

Table VII. Reported amputation rates after vascular injury

\begin{tabular}{lll}
\hline Author & $\begin{array}{l}\text { Number } \\
\text { of cases }\end{array}$ & $\begin{array}{l}\text { Amputation } \\
\text { rate (per cent) }\end{array}$ \\
\hline Hardy and Tibbs 1960 & 11 & 63 \\
Porter 1967 & 24 & 37 \\
Rich et al 1974 & 77 & $33^{*}$ \\
Robbs and Baker 1978 & 48 & 25 \\
Allen et al 1984 & 14 & 42 \\
Meek and Robbs 1984 & 83 & 19 \\
Wilson et al 1987 & 27 & $37^{*}$ \\
Howard and Makin 1990 & 35 & 20 \\
\hline
\end{tabular}

- numbers with skeletal injury not given

The amputation rate for lower limb vascular injuries, even in recent series, varies considerably (Table VII), and our rate of $20 \%$ (with co-existent fractures) is one of the lowest. For open fractures our amputation rate was $25 \%$. Recent studies from North America have been pessimistic about the results for open fractures with vascular involvement (Caudle and Stern 1987; Hansen 1987), but the higher amputation rates may reflect a different aetiology and spectrum of severity of associated injury. The results of our study indicate that, at least in the United Kingdom, aggressive efforts towards limb salvage are worthwhile. 
Conclusions. Lower limb fractures with an associated vascular disruption carry a high risk of amputation. It is recommended that urgent vascular reconstruction with vein graft, should be followed by stabilisation of the fracture with an external fixator.

The authors are indebted to the consultant orthopaedic surgeons of Nottingham and Derby, and to Mr B. R. Hopkinson and Mr K. Callum, consultant vascular surgeons, for allowing us to report their patients.

No benefits in any form have been received or will be received from a commercial party related directly or indirectly to the subject of this article.

\section{REFERENCES}

Allen MJ, Nash JR, Ioannidies TT, Bell PRF. Major vascular injuries associated with orthopaedic injuries to the lower limb. Ann R Coll Surg Engl 1984; 66:101-4.

Caudle RJ, Stern PJ. Severe open fractures of the tibia. J Bone Joint Surg [Am] 1987; 69:801-7.

Connolly JF, Whittaker D, Williams E. Femoral and tibial fractures combined with injuries to the femoral or popliteal artery: a review of the literature and analysis of fourteen cases. J Bone Joint Surg [Am] 1971; 53-A :56-68.

De Bakey ME, Simeone FA. Battle injuries of the arteries in World War II: an analysis of 2471 cases. Ann Surg 1946; 123:534-79.

Doty DB, Treiman RL, Rothschild PD, et al. Prevention of gangrene due to fractures. Surg Gynecol Obstet 1967; 125:284-8.
Hansen ST Jr. Editorial. The type-IIIC tibial fracture: salvage or amputation. J Bone Joint Surg [Am] 1987; 69-A:799-800.

Hardy EG, Tibbs DJ. Acute ischaemia in limb injuries. Br Med J 1960; i:1001-5.

Krige JEJ, Spence RAJ. Popliteal artery trauma : a high risk injury. Br J Surg 1987; 74:91-4.

Makin GS, Howard JM, Green RL. Arterial injuries complicating fractures or dislocations: the necessity for a more aggressive approach. Surgery 1966; 59:203-9.

Meek AC, Robbs JV. Vascular injury with associated bone and joint trauma. Br J Surg 1984; $71: 341-4$.

Porter MF. Arterial injuries in an accident unit. Br J Surg 1967; 54 : $100-5$

Rich NM, Baugh JH, Hughes CW. Popliteal artery injuries in Vietnam. Am J Surg 1969; 118:531-4.

Rich NM, Metz CW Jr, Hutton JE Jr, Baugh JH, Hughes CW. Internal versus external fixation of fractures with concomitant vascular injuries in Vietnam. J Trauma 1971; 11:463-73.

Rich NM, Jarstfer BS, Geer TM. Popliteal artery repair failure : causes and possible prevention. J Cardiovascular Surg (Torino) 1974; 15:340-51.

Robbs JV, Baker LW. Arterial trauma involving the lower limb. $J$ Trauma 1978; 18:324-8.

Waddell JP, Lenczner EM. Arterial injury associated with skeletal trauma. Injury 1974-5; 6:28-32.

Wilson RG, Allsopp RH, Dickinson PH, et al. External vascular trauma : twenty years experience in Newcastle upon Tyne. $J \boldsymbol{R}$ Coll Surg Edinb 1986; $31: 72-5$. 